\title{
Permeability of a lower Albian carbonate reservoir in Campos Basin determined by artificial intelligence techniques together with well logs, cores and geological data
}

Mohammed Saad Al-lahham \& Abel Carrasquilla, UENF/CCT/LENEP, Macaé - RJ, Brazil

Copyright 2018, SBGf - Sociedade Brasileira de Geofísica

Este texto foi preparado para a apresentação no VIII Simpósio Brasileiro de Geofísica, Salinópolis, 18 a 20 de setembro de 2018 . Seu conteúdo foi revisado pelo Comitê Técnico do VIII SimBGf, mas não necessariamente representa a opinião da SBGf ou Técnico do VIII SimBGf, mas não necessariamente representa a opinião da SBGf ou
de seus associados. É proibida a reprodução total ou parcial deste material para propósitos comerciais sem prévia autorização da SBGf.

\begin{abstract}
This work determines the permeability of a lower Albian carbonate reservoir of Oilfield $B$ in Campos Basin, employing artificial intelligence $(\mathrm{Al})$ modern techniques together with a dataset composed of well logs, lithological information and sample laboratory measurements of permeability and porosity. Well logs are formed by gamma ray, density, sonic, neutron porosity and SDR permeability logs. Al techniques as fuzzy logic (FL), artificial neural network (ANN) and genetic algorithm (GA) were applied in three wells, being the first used for learning and the others as blind tests. ANN obtained better performance compared to the $\mathrm{FL}$, but the results have become better with GA.
\end{abstract}

\section{Introduction}

Permeability is considered one of the most important petrophysical properties of reservoirs and it is a measure of the ability of a porous material, often, a rock or an unconsolidated material, to allow fluids to pass through it. The permeability of a medium is linked to the porosity, but also to the shapes of the pores in the medium and their level of connectedness (Lucia, 2007).

$\mathrm{Al}$ is intelligence demonstrated by machines, in contrast to the natural intelligence displayed by humans and other animals. In computer science, Al research is defined as the study of intelligent agents: any device that perceives its environment and takes actions that maximize its chance of successfully achieving its goals. Informally, the term artificial intelligence is given when a machine mimics cognitive functions that humans relate with other human minds, such as learning and problem resolving. The traditional goals of $\mathrm{Al}$ research include reasoning, knowledge representation, planning, learning, natural language processing, perception and the ability to move and manipulate objects. General intelligence is among the field's long-term goals. Approaches include statistical methods, computational intelligence, and traditional symbolic Al. Many tools are used in Al, including versions of search and mathematical optimization, ANN, FL and methods based on statistics, probability and economics. The AI field draws upon computer science, mathematics, psychology, linguistics, philosophy and many others (Russell et al., 2003).

This work contributes in the use of a database of geophysical well logging and petrophysical laboratory data to help characterize the carbonate reservoir of Oilfield B, located in the Campos Basin. This basin is the one that produces the most oil in the Brazilian continental margin. In it there are fields with the presence of Albian carbonate reservoirs, with average porosity and permeability of $25 \%$ and $250 \mathrm{mD}$, respectively. This reservoir belongs to Quissamã Formation, which is formed by grainstones and packstones, constituted by oncoids, ooids, peloids and diverse bioclasts, associated with NE shoals deposited in high to moderate energy environment. Where the carbonates cover about $7 \%$ of the Earth's surface, but they hold more than $60 \%$ of the world's oil reserves and $40 \%$ of gas, with $70 \%$ corresponding to the giant fields of the Middle East (Bruhn et al., 2003).

\section{Methodology}

The study was made via applying three methods of artificial intelligence: ANN (Graupe, 2013), FL (Chen \& Pham, 2001.) and GA (Coley,1999), through getting into four well logging data for wells 17, 29 and 38 (Figure 1). Altogether these three wells belong to the same Oilfield B in Campos Basin. The well logs, that served as input to FL and ANN, were gamma ray, density, sonic and neutron porosity (Ellis \& Singer, 2007). In both cases the permeability is the output parameter and GA serves as the optimizer of both estimates, since they enter as input to decrease the adjustment error. As targets for fit, permeability laboratory measurements on samples and in wells (SDR) were used. This last was derived from the nuclear magnetic resonance (NMR) log and proposed by Schlumberger Doll Research (Coates, et al., 1999.). As a measure of the adjustment quality between the estimates and the targets, the Pearson correlation coefficient $\left(R^{2}\right)$ and Mean Square Error (MSE) were utilized. All the tests were performed using the modules present in Matlab (Matlab, 2016) and Interactive Petrophysics (IP, 2016) programs.

\section{Results}

All the methodology suggested in this study was applied for the three wells, using ANN, FL e GA approaches and targeting the permeabilities obtained in laboratory tests and the SDR, which is obtained in boreholes. Well 17 served as training and wells 29 and 38 as blind tests. However, for lack of space to show all the results, we will only show those that refer to the training well 17.

Thus, Figure 2 shows the adjustments achieved using the three techniques in well 17 with IP as software, by means of SDR permeability data as target. Table 1 shows the fit errors, which supply a quantitative means to measure the functioning of each advance. In this case, LF took first place, with GA in second and ANN in third, all using MSE criteria and in the $R^{2}$ coefficient. In the case of using Matlab as software and SDR permeability as target in well 17 with the three techniques, Figure 3 shows the results 
and Table 2 displays the performance of each technique in the form of fit errors. At this rate, LF took the third place in both error criteria, with GA in second in MSE criterion and first in $R^{2}$ coefficient. On the other hand, ANN was first in MSE criterion and second in $\mathrm{R}^{2}$ coefficient.

In the case of using IP as software, but now the permeability laboratory experimental data as target, Figure 4 shows the fits achieved using the three techniques in well 17. Table 3 , on the other hand, displays the performance of each technique in the form of fit errors. On this occasion, the rating showed GA as first in both error criteria, ANN was third in MSE criterion and second in $R^{2}$ coefficient, whereas LF took the second place in MSE criterion and third in $\mathrm{R}^{2}$ correlation coefficient. When the Matlab software was used with the permeability laboratory experimental data as target, Figure 5 displays the results and Table 4 shows the quantitative values of the performance quality. Thus, GA was the first for both criteria error, ANN was third in MSE criterion and second in $\mathrm{R}^{2}$ coefficient, while LF was the second in MSE criterion and third in $\mathrm{R}^{2}$ coefficient.

\section{Conclusions}

The application of Al systems to permeability estimates was found satisfactory. Although, it is not easy to construct a FL system using the Matlab program, which must set rules previously. The IP software generates the main rules automatically, therefore, its results were more acceptable. In the case of the ANN, the weights in IP software are calculated in the training zone of the first well and then applied to other wells. But in Matlab, the weights are calculated randomly for each well and, in this way, an ANN validation obtained more reasonable estimates. The reductions in errors were later achieved by the GA system through the weights acquired in training, when it was able to optimize the FL and ANN estimates. In some cases, the improvement did not represent a significant reduction of the error in comparison to ANN system. In the permeability validation, ANN showed a greater approximation in relation to FL algorithm, and, as expected, GA optimization achieved the best result in both validations. Nevertheless, the optimal weights calculated in this process did not represent the optimal ones. However, since ANN and GA were obtained by minimizing the MSE error between the real curve and the estimate, this same error was used to evaluate the best approximations among the constructed intelligent systems. After all, the optimum combination of one well will hardly be optimal for another well, especially when it comes from carbonates.

\section{Acknowledgements}

We thank UENF / LENEP for the infrastructure, CNPq for the research grant, LR Senergy for the IP software license, and Petrobras / ANP for the dataset and research resources.

\section{References}

Bruhn, C.; Gomes, J.; Lucchese, C. \& Johann, P. 2003. Campos basin: reservoir characterization and manage- ment - historical overview and future challenges. Offshore Technology Conference. Paper OTC 15220.

Coates, G.; Xiao, L. \& Prammer, M. 1999. NMR logging. Principles \& Applications, Halliburton Energy Services Publication, Houston, $234 \mathrm{p}$.

Coley, D. 1999. An introduction to genetic algorithms for scientists and engineers. World Scientific Publishing Company, Singapore, $211 \mathrm{p}$.

Ellis, D. \& Singer, J. 2007. Well logging for earth scientists. Springer, Richmond, UK, 699 p.

Chen, G. \& Pham, T. 2001. Fuzzy sets, fuzzy logic, and fuzzy control systems. CRS Press, Boca Raton, Florida, 328 p.

Graupe, D. 2013. Principles of artificial neural networks. Advanced series in circuits and systems Vol. 7. World Scientific Publishing Co., Singapore, 363 p.

IP. 2016. Interactive Petrophysics Basic User's Guide, Norwegian University of Science and Technology, Oslo, $19 \mathrm{p}$.

Lucia, J. 2007. Carbonate reservoir characterization, an integrated approach. Springer-Verlag Berlin Heidelberg, $341 \mathrm{p}$.

Matlab. 2016. Matlab - the language of technical computing, Language reference manual, The MathWorks, Inc., Prime Park Way Natick, MA, 772 p.

Russell, S. \& Norvig, P. 20003. Artificial intelligence: a modern approach. Prentice Hall Series in Artificial Intelligence, Upper Saddle River, New Jersey, 1112 p. 


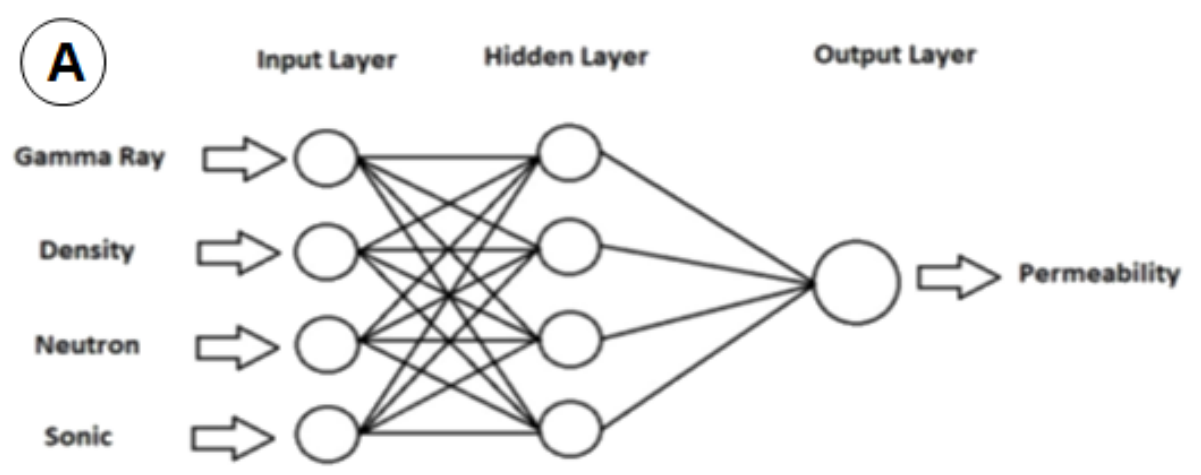

(B) Input Layer Hidden Layer Output Layer

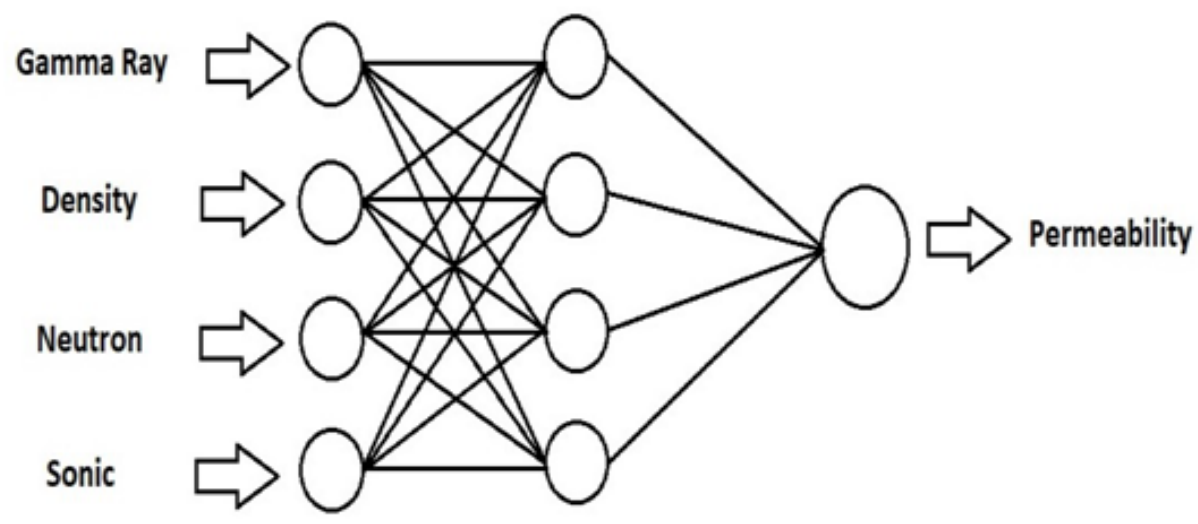

(C)

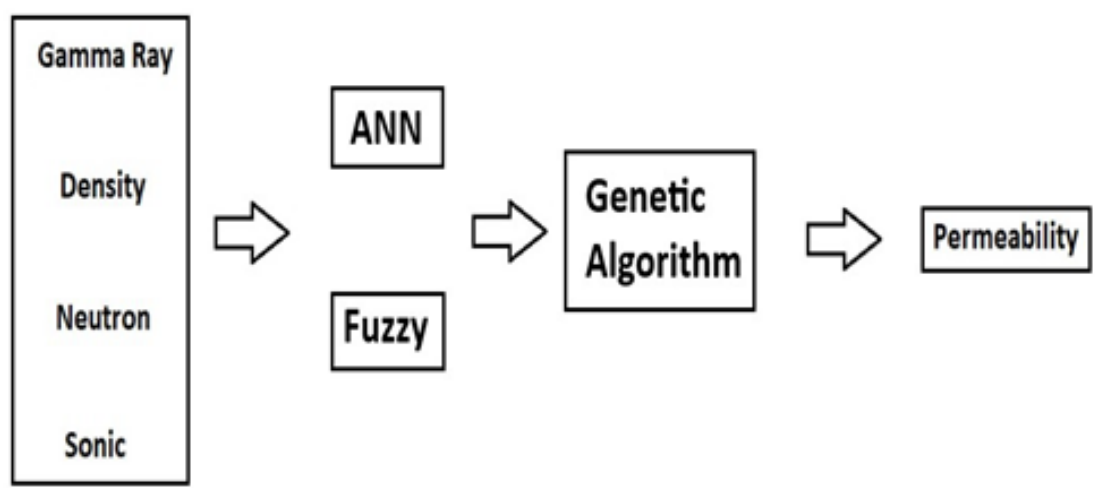

Figure 1. A) Artificial Neural Network, B) Fuzzy Logic and C) Genetic Algorithm schemes. 

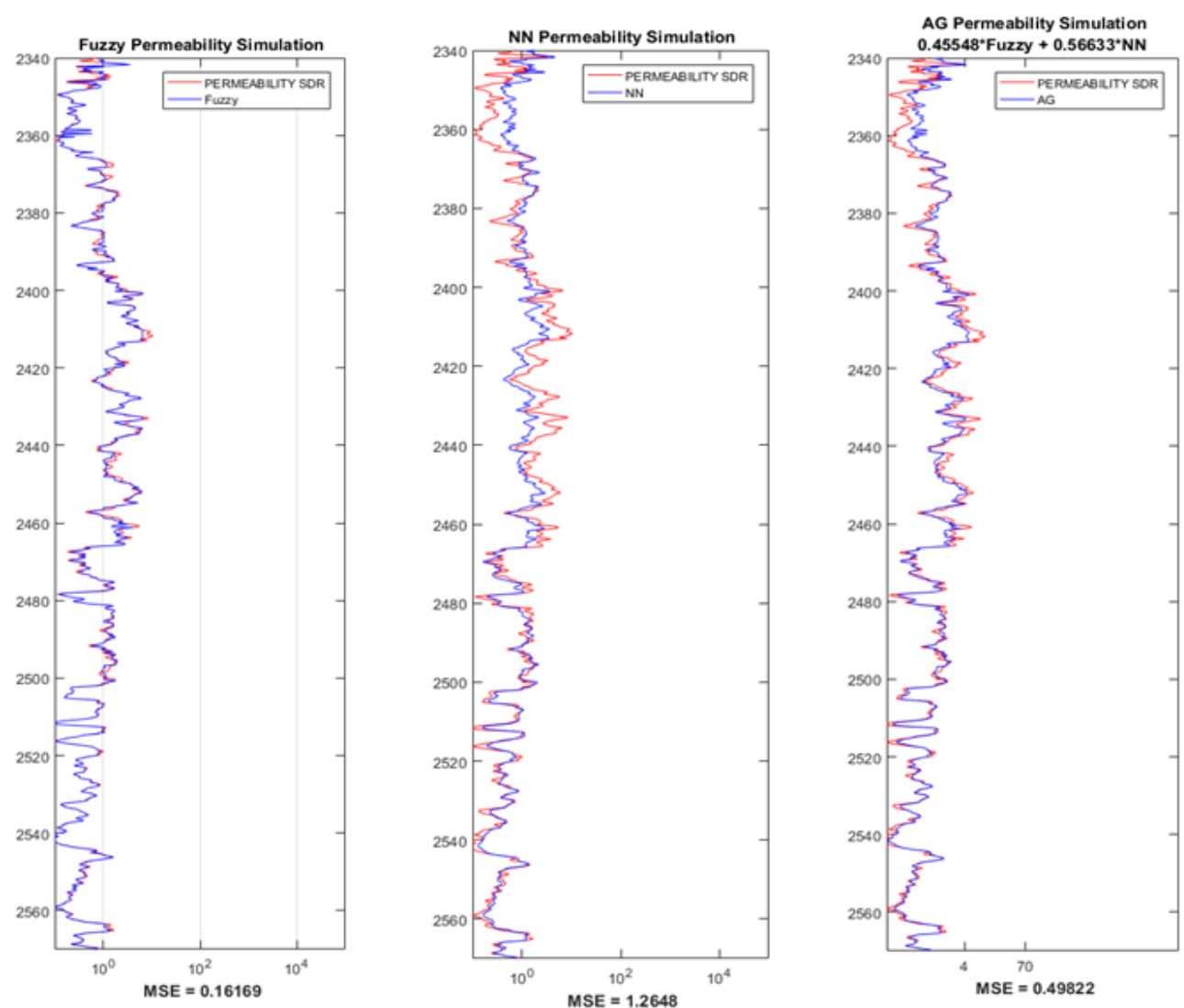

Figure 2. Permeability estimates of well 17 using FL (track 1), ANN (track 2) and GA (track 3) approaches, with SDR permeability as target in IP program.
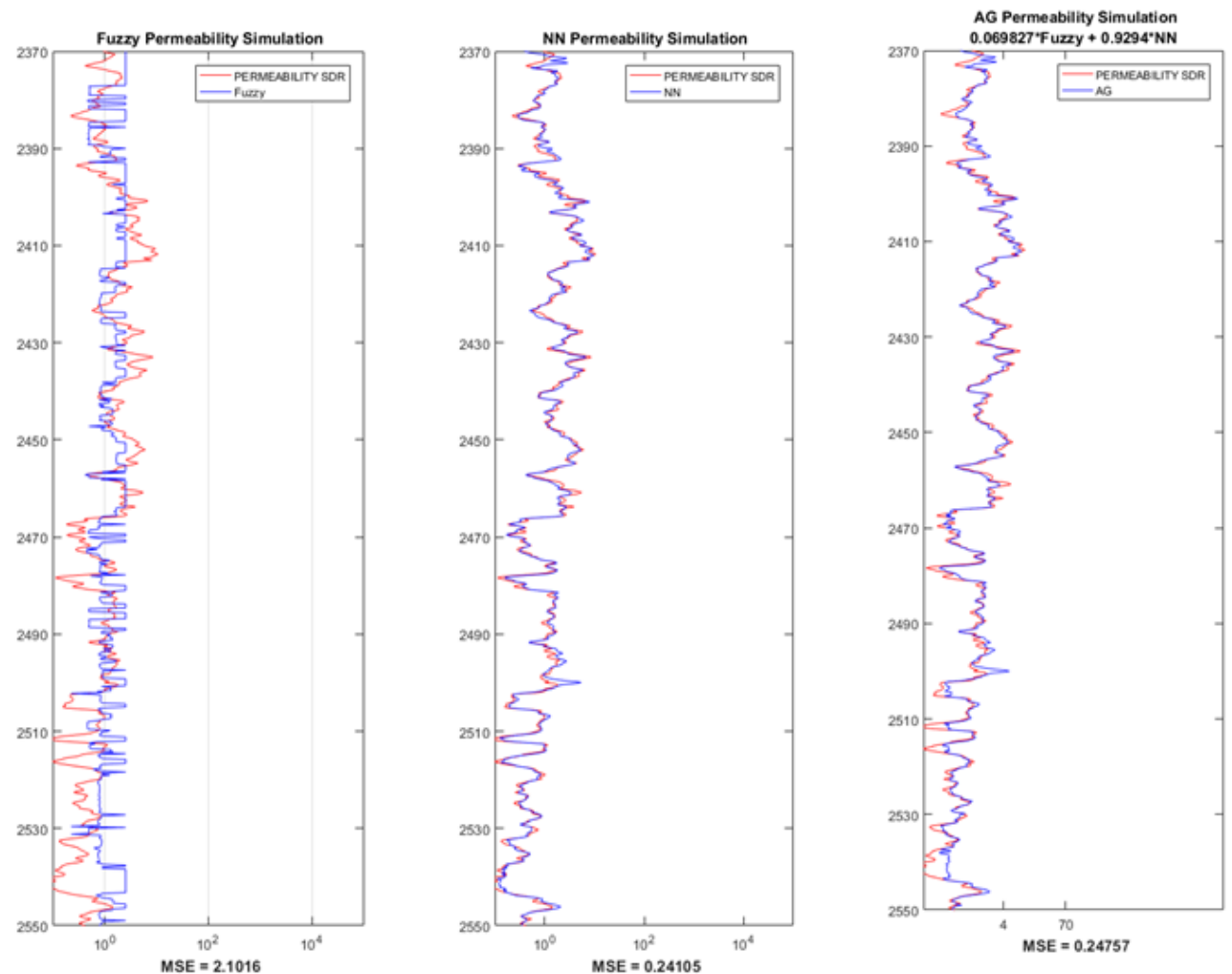

Figure 3. Permeability estimates of well 17 using FL (track 1), ANN (track 2) and GA (track 3) approaches, with SDR permeability as target in Matlab program. 

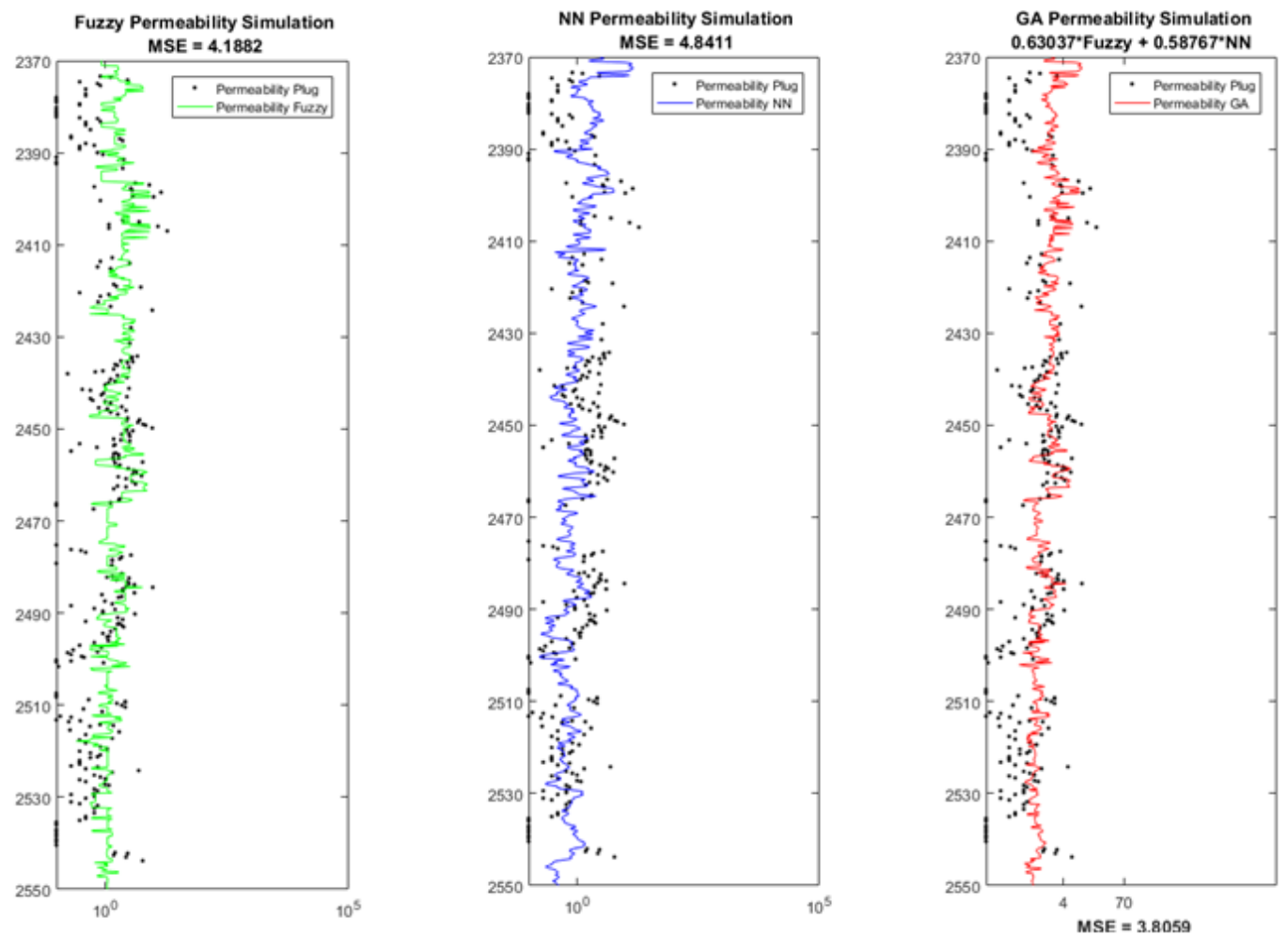

Figure 4. Permeability estimates of well 17 using FL (track 1), ANN (track 2) and GA (track 3) approaches, with laboratory measurements in samples as target in IP program.
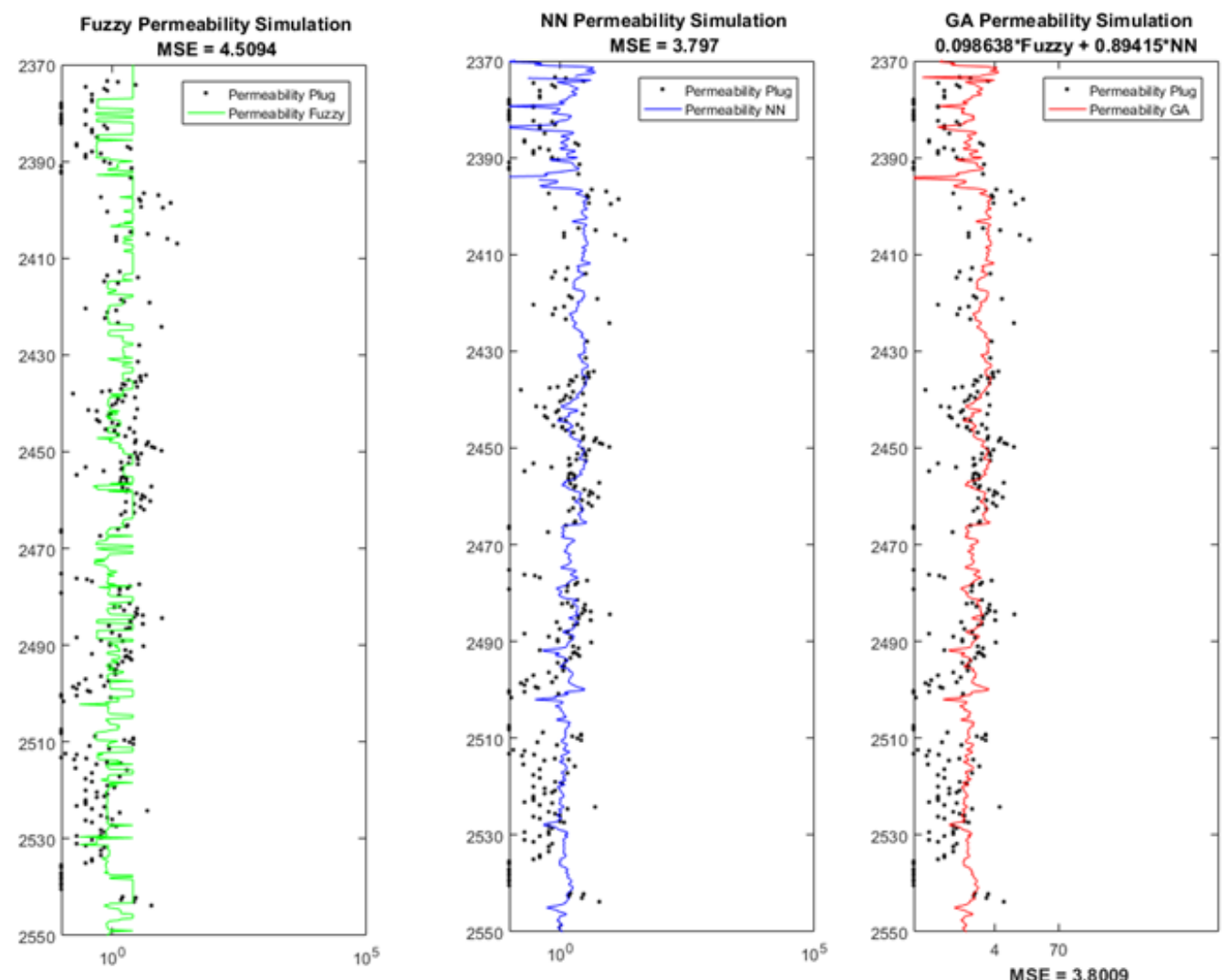

Figura 5. Permeability estimates of well 17 using FL (track 1), ANN (track 2) and GA (track 3) approaches, with laboratory measurements in samples as target in Matlab program. 
Table 1. Comparison of Al techniques with IP program in well 17 and SDR permeability as target.

\begin{tabular}{|c|c|c|c|c|}
\hline \multirow{2}{*}{ Artificial Intelligence techniques } & \multicolumn{4}{|c|}{ Permeability of well 17 using IP program } \\
\cline { 2 - 5 } & MSE $(\mathrm{mD})^{2}$ & Ranking & $\mathrm{R}^{2}$ & Ranking \\
\hline Fuzzy & 0.16169 & 1 & 0.9314 & 1 \\
\hline Neural Network & 1.2648 & 3 & 0.6376 & 3 \\
\hline Genetic Algorithm & 0.49822 & 2 & 0.9231 & 2 \\
\hline
\end{tabular}

Table 2. Comparison of Al techniques with Matlab program in well 17 and SDR permeability as target.

\begin{tabular}{|c|c|c|c|c|}
\hline \multirow{2}{*}{ Artificial Intelligence techniques } & \multicolumn{4}{|c|}{ Permeability of well 17 using IP program } \\
\cline { 2 - 5 } & $\mathrm{MSE}(\mathrm{mD})^{2}$ & Ranking & $\mathrm{R}^{2}$ & Ranking \\
\hline Fuzzy & 2.1016 & 3 & 0.5356 & 3 \\
\hline Neural Network & 0.24105 & 1 & 0.9051 & 2 \\
\hline Genetic Algorithm & 0.24757 & 2 & 0.9052 & 1 \\
\hline
\end{tabular}

Table 3. Comparison of Al techniques with IP program in well 17 and permeability laboratory experimental data.

\begin{tabular}{|c|c|c|c|c|}
\hline \multirow{2}{*}{ Artificial Intelligence techniques } & \multicolumn{4}{|c|}{ Permeability of well 17 using IP program } \\
\cline { 2 - 5 } & $\mathrm{MSE}(\mathrm{mD})^{2}$ & Ranking & $\mathrm{R}^{2}$ & Ranking \\
\hline Fuzzy & 4.1882 & 2 & 0.5058 & 3 \\
\hline Neural Network & 4.8211 & 3 & 0.8229 & 2 \\
\hline Genetic Algorithm & 3.8059 & 1 & 0.8618 & 1 \\
\hline
\end{tabular}

Table 4. Comparison of Al techniques with Matlab program in well 17 and permeability laboratory experimental data.

\begin{tabular}{|c|c|c|c|c|}
\hline \multirow{2}{*}{ Artificial Intelligence techniques } & \multicolumn{4}{|c|}{ Permeability of well 17 using IP program } \\
\cline { 2 - 5 } & $\mathrm{MSE}(\mathrm{mD})^{2}$ & Ranking & $\mathrm{R}^{2}$ & Ranking \\
\hline Fuzzy & 4.5094 & 3 & 0.7889 & 1 \\
\hline Neural Network & 3.797 & 1 & 0.7388 & 3 \\
\hline Genetic Algorithm & 3.8009 & 2 & 0.7734 & \\
\hline
\end{tabular}

